\begin{tabular}{c|c|c}
\hline \hline $\begin{array}{c}\text { Vol. 29: 137-148, 2020 } \\
\text { https://doi.org/10.3354/ab00731 }\end{array}$ & $\begin{array}{c}\text { AQUATIC BIOLOGY } \\
\text { Aquat Biol }\end{array}$ & Published October 22 \\
\hline \hline
\end{tabular}

\title{
Effects of habitat on reef fishes biodiversity and composition in rocky reefs
}

\author{
Xu Zeng ${ }^{1}$, Kisei R. Tanaka ${ }^{2}$, Mackenzie Mazur ${ }^{3}$, Kai Wang ${ }^{4}$, Yong Chen ${ }^{3}$, \\ Shouyu Zhang ${ }^{4, *}$ \\ ${ }^{1}$ School of Oceanography, Shanghai Jiao Tong University, Shanghai 200030, PR China \\ ${ }^{2}$ Monterey Bay Aquarium, Monterey, CA 93940, USA \\ ${ }^{3}$ School of Marine Sciences, University of Maine, Orono, ME 04469, USA \\ ${ }^{4}$ College of Marine Ecology and Environment, Shanghai Ocean University, Shanghai 201306, PR China
}

\begin{abstract}
Reef fish are highly valuable to human society - socially, nutritionally and economically. However, they are vulnerable to both overfishing and habitat degradation. Understanding the community structure and habitat associations of reef fish is important for their management and conservation. Using a gillnet survey conducted in a subtropical rocky reef area of Ma'an Archipelago, China, we developed habitat models linking reef fish diversity and community composition with habitat factors. The parsimonious generalized additive model results showed that higher reef fish diversity was associated with southern shallower water, temperature of $25^{\circ} \mathrm{C}$, lower levels of dissolved oxygen and chlorophyll $a$, and rock bottom type. The multivariate generalized linear model identified that month, depth, bottom type, and location significantly influenced the local reef fish; these habitat variables explained $18 \%$ of the variation in reef fish community composition. However, the lack of strong patterns and correlations between species derived from the joint species distribution model revealed that reefs within our study area are difficult to classify based on habitat-driven patterns in their associated reef fish assemblages. These findings enhance our understanding of the habitat effects on reef fish diversity and community composition and have relevance for the management of reef fish, including habitat zonation and deployment of artificial reefs.
\end{abstract}

KEY WORDS: Reef fishes · Rocky reefs habitat · Ma'an Archipelago · Habitat models · Gillnet survey

\section{INTRODUCTION}

Reef fish are socially, nutritionally, and economically valuable to human society (Sadovy 2005). However, they are vulnerable to overfishing because of their long-lived, slow-growing, and limited-dispersal characteristics (Parker et al. 2000, Love et al. 2006). Rocky reefs, the habitat of reef fish, are also under anthropogenic stress as a result of port construction, mariculture, and destructive bottom trawl fisheries (Neira \& Cantera 2005). The bladder of reef fish creates a relatively narrow zone of neutral buoyancy in shallow waters which makes them easily injured by forced up-and-down movements through the water

${ }^{*}$ Corresponding author: syzhang@shou.edu.cn column (Parker et al. 2006); therefore, release strategies for reef fish are often ineffective (Parker et al. 2000, Yamanaka \& Logan 2010). Ecosystem-based fisheries management (EBFM), the establishment of marine protected areas (MPAs), and construction of artificial reefs are approaches aimed at conserving these vulnerable fish, but their effectiveness requires a robust understanding of reef fish structure, including the effects of habitat on fish assemblages.

Physical and biological habitat variables can drive the spatial variation of populations and assemblages of various reef inhabitants (Guidetti et al. 2004, Schroeter et al. 2015). Nutrient availability and temperature influence local fish community structure

(C) The authors 2020. Open Access under Creative Commons by Attribution Licence. Use, distribution and reproduction are unrestricted. Authors and original publication must be credited. 
by altering recruitment and post-recruitment processes (Connell \& Jones 1991, Tupper \& Boutilier 1997), prey availability (Warfe \& Barmuta 2004), and interspecies interactions (Hixon \& Beets 1993, Johnson 2006). The magnitude of the associations between fish assemblages and habitat variables has been a key criterion for the designation, management, and assessment of MPAs (Anderson \& Millar 2004, García-Charton et al. 2004). Artificial reefs are commonly used for fishery-enhancement programs (Smith et al. 2017), but uncertainties regarding their design and site selection can influence the targeted marine communities. However, associations between fish assemblages and habitat variables have not been explicitly incorporated into the deployment of artificial reefs (Parsons et al. 2016). Recent studies of associations between species and habitat variables focused on tropical (Beger \& Possingham 2008, Richardson et al. 2017) and temperate (Tuya et al. 2009, Cameron et al. 2014, Parsons et al. 2016) marine ecosystems. Thus, the effective conservation and enhancement for reef fish in subtropical rocky reefs has not been well promoted.

Habitat suitability modeling has become a common ecological tool to understand how physical and biological variables influence species distribution and assemblages (Guisan \& Zimmermann 2000, Cameron et al. 2014, Nash et al. 2016, Parsons et al. 2016). Generalized additive models (GAMs) are one of the most commonly used statistical modeling techniques for habitat suitability modeling, as GAMs can explore nonlinear relationships between response (e.g. species presence or abundance) and explanatory (e.g. temperature, depth, salinity, etc.) variables. However, potential biotic interactions (e.g. species co-occurrence) are not included in GAM-based analyses. The multivariate generalized linear model (MGLM) and joint species distribution model (JSDM) have been developed for analyzing multivariate community abundance data (Hui 2016), and have improved our ability to model community-level responses to physical and biological variables, while accounting for species correlations (Warton et al. 2015). Here, we used a combination of these modeling methods to make our analysis more comprehensive and in-depth.

In Ma'an Archipelago, in the East China Sea, the rocky reefs are under high anthropogenic pressure from road/port construction and fishing (Wang et al. 2012). Based on a combination of the life-history characteristics of the reef fish and the status of their habitat in Ma'an Archipelago, there is an urgent need to conserve them. In this study, we examined the effects of habitat on reef fish diversity (using a
GAM) and community composition (using a MGLM and a JSDM) in Ma'an Archipelago. The results of this study will further our understanding of the associations between habitat and reef fish in subtropical rocky reefs and provide guidance for the management of reef fish and their habitats, including habitat zonation and the deployment of artificial reefs.

\section{MATERIALS AND METHODS}

\subsection{Study area}

Ma'an Archipelago is located at the center of the Zhoushan fishing ground, where the confluence of the Yangtze River, Qiantang River, Yellow Sea cold water mass, Taiwan Warm Current surface water, and Taiwan Warm Current deep water occurs (Zhang et al. 2007). This complex hydrological environment makes Ma'an Archipelago a feeding ground for many marine organisms (Wang et al. 2012). The coast of Gouqi Island in Ma'an Archipelago is dominated by Sargassum horneri, which provides feeding and spawning areas as well as shelter for a variety of invertebrates and fish (Chen et al. 2015). Ma'an Archipelago is under high fishing pressure, with more than 150000 fishermen $\mathrm{yr}^{-1}$ operating fishing vessels in the area (Lin 2017). In order to protect the fishery, an MPA and ongoing artificial reef program were established. The MPA has been moderately effective, although its management still needs to be improved (Sun 2018). This area is closed to fishing from 1 May to 1 September.

\subsection{Survey data}

This study was based on a fishery-independent multi-mesh gillnet survey conducted in Ma'an Archipelago from January to December in 2009 (Fig. 1). A total of 21 sites were sampled during the survey; details of the total sample composition and sampling months for each site can be found in Wang et al. (2012). Each site was sampled for 24 h by 2 groups of parallel gillnets. One group consisted of 4 connected gillnets with mesh sizes of $2.5,3.4,4.3$, and $5.8 \mathrm{~cm}$, each net being $1.5 \mathrm{~m}$ in height and $3.75 \mathrm{~m}$ long $(=1.5 \mathrm{~m}$ height $\times 15 \mathrm{~m}$ total length). The other group consisted of 4 connected gillnets with mesh sizes of 5,6 , 7 , and $8 \mathrm{~cm}$, each net being $2.4 \mathrm{~m}$ in height and $7.5 \mathrm{~m}$ long (=2.4 m height $\times 30 \mathrm{~m}$ total length). Catches from the 2 gillnets were combined for further analysis. Depth $(\mathrm{m})$, temperature $\left({ }^{\circ} \mathrm{C}\right)$, salinity $(\% \circ)$, dis- 


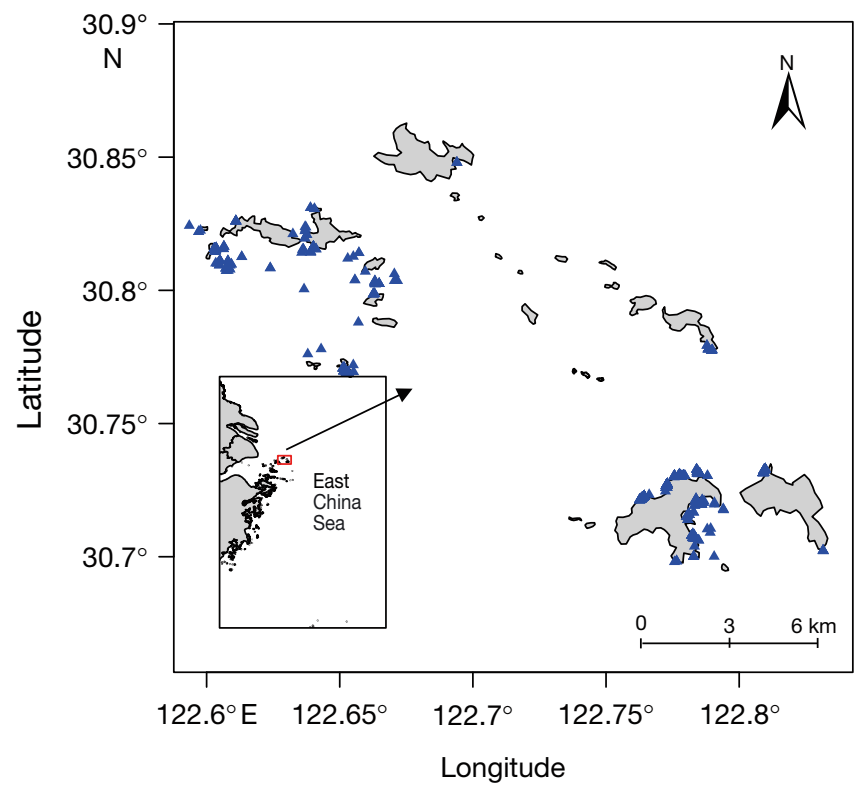

Fig. 1. Gillnet survey sites in Ma'an Archipelago; blue triangles: sampling locations

solved oxygen (DO; $\mathrm{mg} \mathrm{l}^{-1}$ ), chlorophyll a (chl $a_{i} \mathrm{mg}$ $\mathrm{I}^{-1}$ ), and turbidity (NTU) at each site were measured with a water quality measuring instrument (AAQ1183). Using a grab sampler at each site, mud, mixed sand, rock, and mud (srm), sand, mixed sand and rock (sr), and rock were identified.

\subsection{GAM}

A GAM was used to assess the effects of habitat variables on reef fish diversity. Three indices of diversity were modeled as response variables: the total number of species $(S)$, Shannon-Wiener index $\left(H^{\prime}\right)$, and Simpson's diversity index $(D)$. $H^{\prime}$ and $D$ were calculated by the following formulae:

$$
\begin{gathered}
H^{\prime}=-\sum_{i=1}^{S} P_{i} \operatorname{Ln} P_{i} \\
D=1-\sum_{i}^{S} P_{i}^{2}
\end{gathered}
$$

where $i$ is the number of $i^{\text {th }}$ species and $P_{i}$ is the proportion of $i^{\text {th }}$ species in the total number of species. Location (longitude and latitude), month, depth (m), bottom type, temperature $\left({ }^{\circ} \mathrm{C}\right)$, salinity $(\%), \mathrm{DO}\left(\mathrm{mg} \mathrm{l}^{-1}\right)$, chl a $\left(\mathrm{mg} \mathrm{l}^{-1}\right)$, and turbidity (NTU) were selected as explanatory variables.

To check the multicollinearity of candidate explanatory variables, Spearman's correlation and variance inflation factors (VIFs) were used. Firstly, we calculated the Spearman coefficients between vari- ables. If the coefficient between 2 variables was $>0.7$ (Jaureguizar et al. 2016), a variable explaining less variation of reef fish diversity in the GAM was removed. We further detected collinearity using VIFs, where variables with VIF > 10 were removed (Borcard et al. 2011). To assess the influence of DO along the depth gradient, an interaction between DO and depth was included in the models. An interaction between longitude and latitude was also included to assess the spatial influence.

The general formulation of a GAM can be expressed as:

$$
\log \left[E\left(y_{i}\right)\right]=\alpha+\sum_{i=1}^{p} f\left(x_{i}\right)+\varepsilon
$$

where $y_{i}$ is the response variable, $\alpha$ denotes an intercept term, $f$ denotes the non-parametric cubic spline smooth function, $x_{i}$ denotes the $i^{\text {th }}$ explanatory variable, and $\varepsilon$ is the residual error term. The GAM was fitted with a Tweedie family distribution to account for large proportion of zeros within response variables (Jaureguizar et al. 2016). A Tweedie GAM parameter, $p$, can be a value between 1 and 3 , where $p=1$ corresponds to Poisson distribution and $p=3$ corresponds to inverse Gaussian distribution (Tweedie 1984). The Tweedie GAM developed in our study was fitted by restricting $p$ between 1 and 2, which defined a compound Poisson that can model positive values and zeros at once. Model selection was carried out through backwards selection based on Akaike's information criterion (Wood 2017); model assumptions were evaluated by examining the plots of residuals. The relative importance of each variable in the GAM was calculated by (1) assessing the original adjusted $\mathrm{R}^{2}$ and smooth parameter of each variable from the best-fitting GAM; and (2) removing a variable and re-modeling the other variables with their smooth parameter derived from (1) (above) in a new GAM to get a new adjusted $\mathrm{R}^{2}$. The relative importance of the removed variable was evaluated by the new adjusted $\mathrm{R}^{2}$ minus the original adjusted $\mathrm{R}^{2}$ (Wood 2005). All statistical analyses were conducted using the ' $\mathrm{mgcv}^{\prime}$ package (Wood \& Wood 2007) in R v.3.6.1 (R Development Core Team 2019).

\subsection{MGLM}

A MGLM was used to model the relationship between the habitat variables and reef fish community composition. A MGLM fits a separate GLM for each species; resampling-based hypothesis testing is then used to find predictors that influence multivariate abundances (Yi et al. 2012). The MGLM in our 
study was fitted with a negative binomial error distribution. Variation in species composition explained by predictors was calculated by the 'anova.manyglm' function in packaqge 'mvabund' (Yi et al. 2012).

\subsection{JSDM}

We used a JSDM to further explore our multispecies data set. A JSDM incorporates the impact of habitat predictors and interspecific interactions in a single model (Hui 2016). Two latent variables were included in our JSDM to create an unconstrained ordination to visualize the main trends between reef sites based on their species composition. Latent variables account for unknown or unmeasured variables, and enable an unconstrained ordination for visualizing site and species patterns by inducing correlations between taxa (Warton et al. 2015). There was no row effect in our JSDM, which means that the ordination patterns were driven by differences in both abundance and species composition between sites. The residual correlation matrices were also evaluated to explore correlations between species (i.e. co-occurrence) due to habitat factors and unmeasured variables. The JSDM was built using the $\mathrm{R}$ package 'boral' (Hui 2016).

\section{RESULTS}

\subsection{Observed species composition}

A total of 12 species of reef fish were identified from the gillnet survey in 2009 (Table 1). The most frequently observed species were Sebastiscus marmoratus, Hexagrammos agrammus, and Hexagrammos otakii representing $63.6,20.3$, and $7.3 \%$ of the total abundance, respectively.

\subsection{Effects of habitat on reef fish diversity}

Turbidity and chl a were highly correlated (correlation: 0.71, p < 0.01) (Fig. 2). Turbidity was removed from the candidate variables, as the GAM including turbidity explained less variation in reef fish diversity than the GAM including chl $a$. The rest of the candidate variables were included in our models because their VIF values were less than 10 (Table 2).

The best-fitting Tweedie-GAM identified that $S$ in Ma'an Archipelago was significantly influenced by chl $a$, temperature, DO, month, bottom type, the
Table 1. Total number of individuals of each species collected in 2009 in Ma'an Archipelago; common names were derived from FishBase (Froese \& Pauly 2019)

\begin{tabular}{|lcc|}
\hline Species & $\begin{array}{c}\text { Common } \\
\text { name }\end{array}$ & $\begin{array}{c}\text { Abundance } \\
\text { (ind. } \mathrm{yr}^{-1} \text { ) }\end{array}$ \\
\hline $\begin{array}{l}\text { Sebastiscus marmoratus } \\
\text { Hexagrammos agrammus }\end{array}$ & $\begin{array}{c}\text { False kelpfish } \\
\text { Spotty-bellied } \\
\text { greenling }\end{array}$ & 1671 \\
Hexagrammos otakii & Fat greenling & 193 \\
Microcanthus strigatus & Stripey & 65 \\
Parajulis poecilepterus & Multicolorfin & 60 \\
& rainbowfish & \\
Pagrosomus major & Red seabream & 40 \\
Acanthopagrus schlegelii & Blackhead seabream & 34 \\
Apogon semilineatus & Half-lined cardinal & 24 \\
Epinephelus akaara & Spinycheek grouper & 4 \\
Oplegnathus fasciatus & Barred knifejaw & 2 \\
Goniistius zonatus & Spottedtail morwong & 1 \\
Enedrias nebulosus & Tidepool gunnel & 1 \\
\hline
\end{tabular}

interaction of latitude and longitude, and the interaction of DO and depth (Table 3). These predictors explained $77.5 \%$ of variation in $S$. The most important predictor for $S$ was the interaction between DO and depth (Table 3). The chl a response curve from the best-fitting model showed higher $S$ at 50, 250, and $>450 \mathrm{mg} \mathrm{l}^{-1}$ (Fig. 3). The temperature response curve showed the highest $S$ at $25^{\circ} \mathrm{C}$ (Fig. 3). The DO response curve showed $S$ decreased with DO (Fig. 3). Higher $S$ was found in May and November (Fig. 3), and the highest $S$ occurred in rock bottom type (Fig. 3). The interaction of depth and DO response map showed higher $S$ associated with 5-15 m depth and DO $<4 \mathrm{mg} \mathrm{l}^{-1}$ (Fig. 3).

$H^{\prime}$ and $D$ were significantly influenced by month, bottom type, chl $a$, and temperature (Table 3 ). These variables explained $42.5 \%$ and $37.5 \%$ of variation in $H^{\prime}$ and $D$, respectively. The most significant factor for $H^{\prime}$ and $D$ was chl a (Table 3 ). Higher values of $H^{\prime}$ and

Table 2. Candidate explanatory variables used in this study. VIF: variance inflation factor; $\mathrm{n} / \mathrm{a}$ : not assessed

\begin{tabular}{|lcc|}
\hline Variable & Type & VIF \\
\hline Longitude $\left(^{\circ}\right)$ & Spatial & 6.70 \\
Latitude $\left(^{\circ}\right)$ & Spatial & 5.58 \\
Bottom type & Abiotic & $\mathrm{n} / \mathrm{a}$ \\
Month & Temporal & $\mathrm{n} / \mathrm{a}$ \\
Depth $(\mathrm{m})$ & Abiotic & 1.59 \\
Temperature $\left({ }^{\circ} \mathrm{C}\right)$ & Abiotic & 3.94 \\
Salinity $(\%)$ & Abiotic & 1.36 \\
Dissolved oxygen $\left(\mathrm{mg} \mathrm{l}^{-1}\right)$ & Abiotic & 3.51 \\
Chlorophyll $a\left(\mathrm{mg} \mathrm{l}^{-1}\right)$ & Abiotic & 1.19 \\
\hline
\end{tabular}




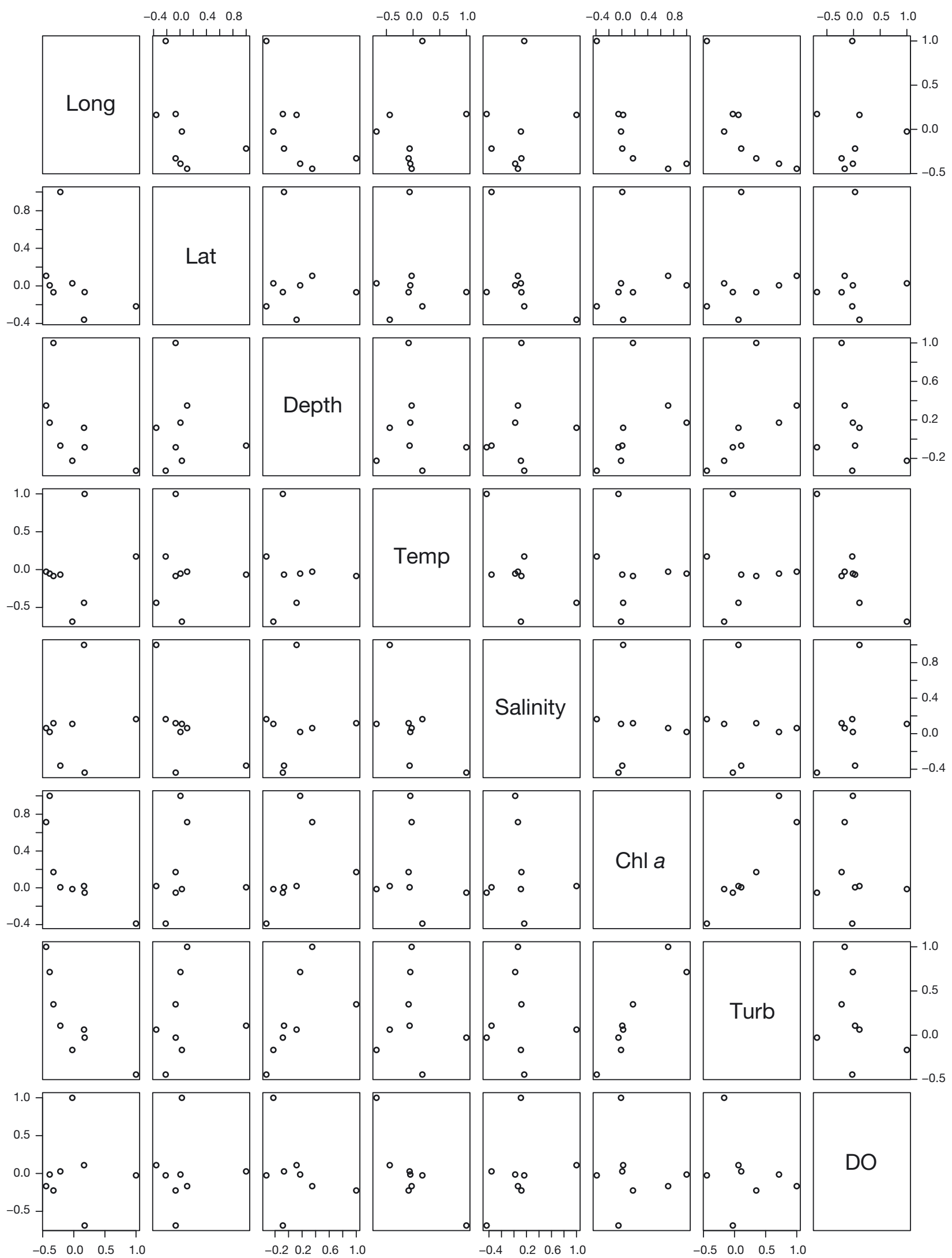

Fig. 2. Spearman correlations between candidate habitat variables (categorical variables were not included). Long: longitude, Lat: latitude, Temp: temperature, Turb: turbidity 
Table 3. Full and best fitting generalized additive models for the total number of reef fish, Shannon-Wiener index, and Simpson's diversity index. Relative importance of predictors for the best fitting model are listed in the last column. edf: estimated degree of freedom; AIC: Akaike's information criterion

\begin{tabular}{|c|c|c|c|c|c|c|}
\hline $\begin{array}{l}\text { Response } \\
\text { variable }\end{array}$ & Model & Formula & edf & $\begin{array}{c}\text { Deviance } \\
\text { explained (\%) }\end{array}$ & AIC & $\begin{array}{l}\text { Predictor's } \\
\text { importance }\end{array}$ \\
\hline \multirow[t]{2}{*}{$\begin{array}{l}\text { Total } \\
\text { number of } \\
\text { reef fish }(S)\end{array}$} & Full & $\begin{array}{c}\mathrm{s}(\text { Latitude,longitude })+\text { month }+ \text { bottom } \\
+\mathrm{s}(\text { chl } a)+\mathrm{s}(\text { temperature })+\mathrm{s}(\mathrm{DO}, \text { depth }) \\
+\mathrm{s}(\text { salinity })+\mathrm{s}(\text { depth })+\mathrm{s}(\mathrm{DO})\end{array}$ & $\begin{array}{c}17.75,2.76,4.02 \\
12.04,2.91,1.00 \\
4.48\end{array}$ & 82.50 & 907.49 & \\
\hline & $\begin{array}{l}\text { Best- } \\
\text { fitting }\end{array}$ & $\begin{array}{c}\mathrm{s}(\text { Latitude,longitude })+\text { month } \\
+ \text { bottom }+\mathrm{s}(\text { chl } a)+\mathrm{s}(\text { temperature }) \\
+\mathrm{s}(\mathrm{DO}, \text { depth })+\mathrm{s}(\mathrm{DO})\end{array}$ & $\begin{array}{c}4.09,7.10,5.85 \\
18.88,5.41\end{array}$ & 77.50 & 905 & $\begin{array}{c}0.035,0.146 \\
0.001,0.029 \\
0.035,0.102, \\
0.012\end{array}$ \\
\hline \multirow[t]{2}{*}{$\begin{array}{l}\text { Shannon- } \\
\text { Wiener } \\
\text { index }\left(H^{\prime}\right)\end{array}$} & Full & $\begin{array}{l}\mathrm{s}(\text { Latitude,longitude })+\text { month }+ \text { bottom } \\
\quad+\mathrm{s}(\text { depth,DO })+\mathrm{s}(\text { salinity })+\mathrm{s}(\mathrm{DO}) \\
+\mathrm{s}(\text { chl } a)+\mathrm{s}(\text { depth })+\mathrm{s}(\text { temperature })\end{array}$ & $\begin{array}{l}2.88,5.72,2.14 \\
1.00,3.98,1.21 \\
1.00\end{array}$ & 49.50 & 351 & \\
\hline & $\begin{array}{l}\text { Best- } \\
\text { fitting }\end{array}$ & $\begin{array}{c}\text { Month }+ \text { bottom }+\mathrm{s}(\mathrm{chl} a) \\
+\mathrm{s}(\text { temperature })\end{array}$ & $4.68,1.00$ & 42.50 & 300.22 & $\begin{array}{l}0.06,0.073 \\
0.087,0.086\end{array}$ \\
\hline \multirow[t]{2}{*}{$\begin{array}{l}\text { Simpson's } \\
\text { diversity } \\
\text { index }(D)\end{array}$} & Full & $\begin{array}{l}\text { s(Latitude, longitude })+ \text { month + bottom } \\
+\mathrm{s}(\text { depth, } \mathrm{DO})+\mathrm{s}(\text { salinity })+\mathrm{s}(\mathrm{DO}) \\
+\mathrm{s}(\operatorname{chl} a)+\mathrm{s}(\text { depth })+\mathrm{s}(\text { temperature })\end{array}$ & $\begin{array}{l}2.88,8.92,1.55 \\
1.00,4.87,1.00 \\
1.00\end{array}$ & 46.30 & 113.5 & \\
\hline & $\begin{array}{l}\text { Best- } \\
\text { fitting }\end{array}$ & $\begin{array}{c}\text { Month + bottom }+\mathrm{s}(\mathrm{chl} a) \\
+\mathrm{s}(\text { temperature })\end{array}$ & $4.84,1.00$ & 37.50 & 61.44 & $\begin{array}{l}0.05,0.056 \\
0.092,0.074\end{array}$ \\
\hline
\end{tabular}
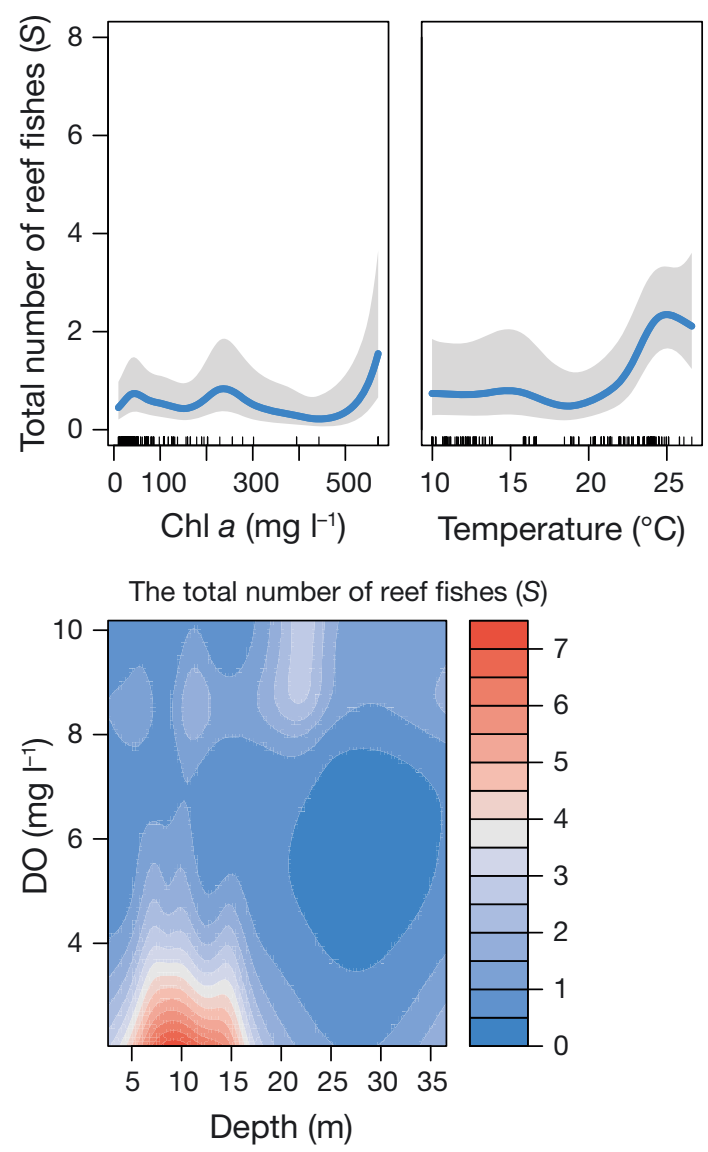
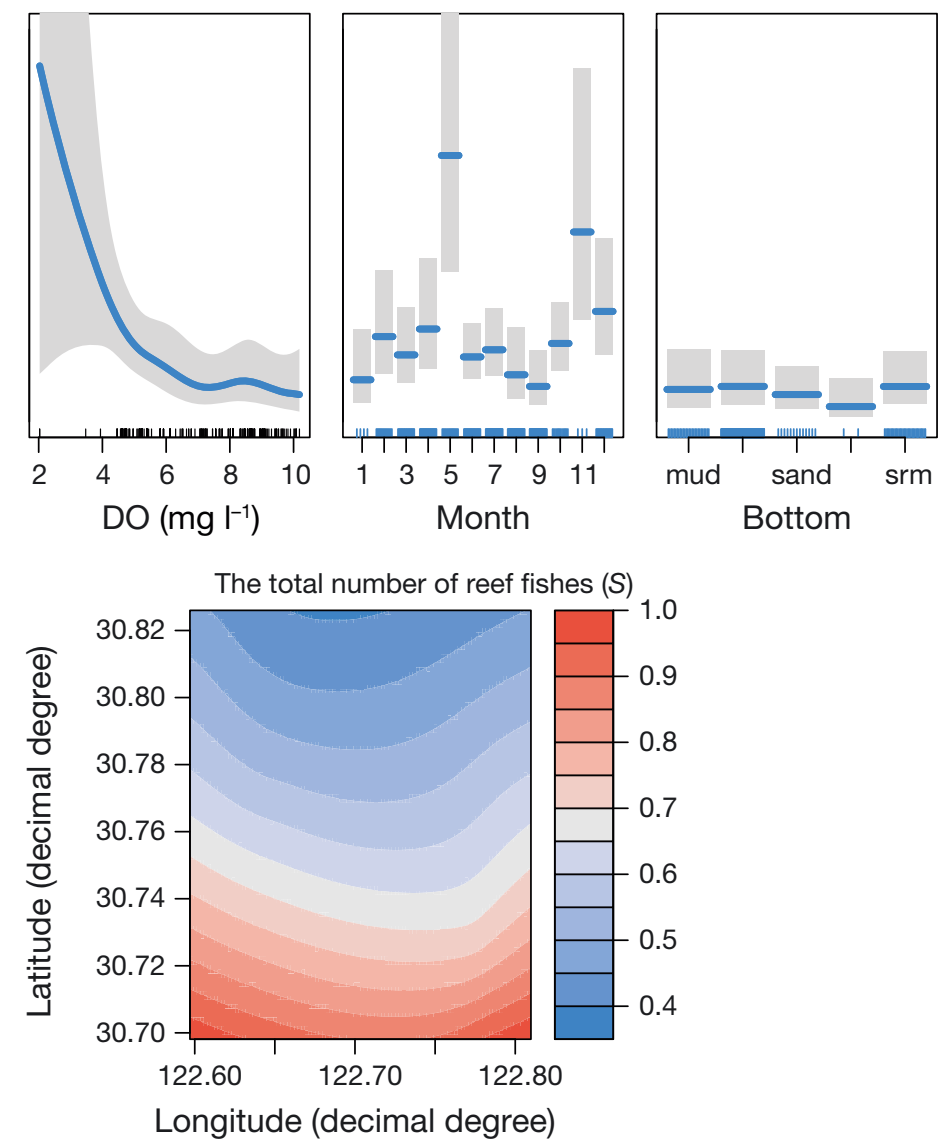

Fig. 3. Fitted back-transformed smoothing curves for significant univariate explanatory variables in the best-fitting generalized additive model explaining the total number of reef fish species. Tick marks on $x$-axis: relative density of observation; gray shading: $95 \%$ CIs 

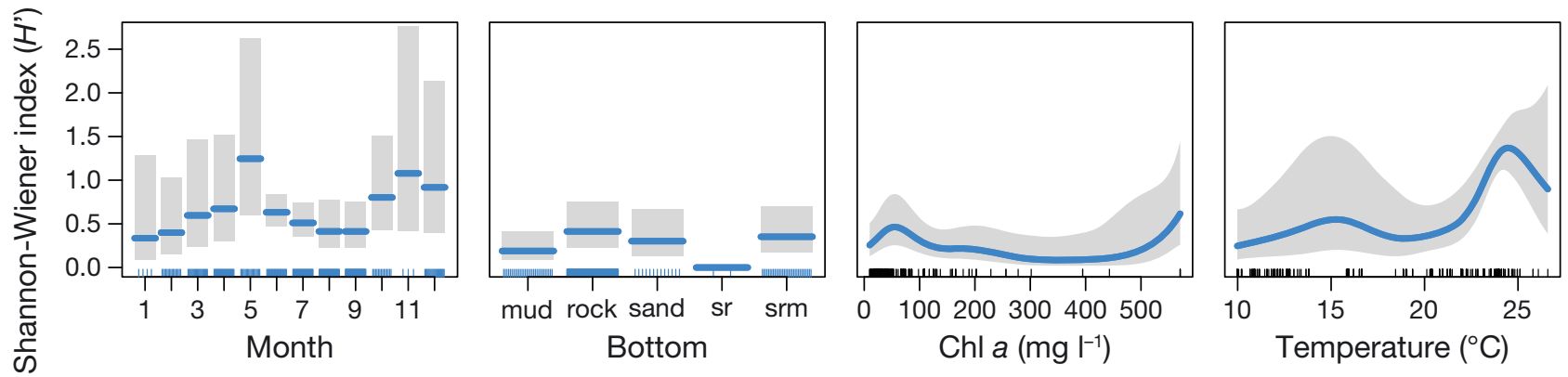

Fig. 4. Fitted back-transformed smoothing curves for significant univariate explanatory variables in the best-fitting generalized additive model explaining the Shannon-Wiener index. Tick marks on $x$-axis: relative density of observation; gray shading: $95 \%$ CIs
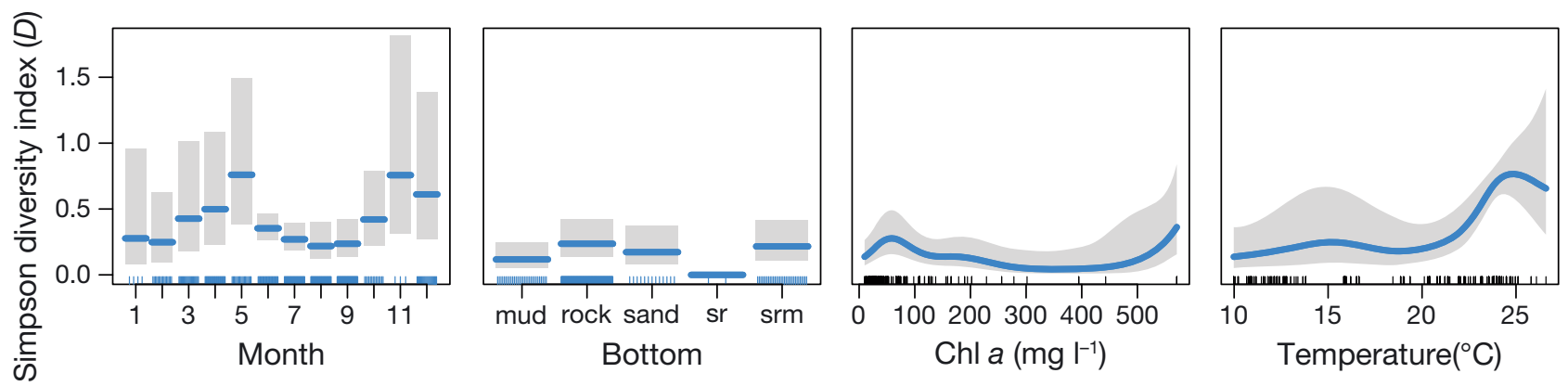

Fig. 5. Fitted back-transformed smoothing curves for significant univariate explanatory variables in the best-fitting generalized additive model explaining Simpson' diversity index. Tick marks on $x$-axis: relative density of observation; gray shading: $95 \%$ CIs

$D$ were found in May and November (Figs. 4 \& 5), and the highest $H^{\prime}$ and $D$ occurred in the rock bottom type (Figs. 4 \& 5). The chl a response curves showed $H^{\prime}$ and $D$ increased with chl a between $0-50$ and $>450 \mathrm{mg} \mathrm{l}^{-1}$ and decreased with chl a between 50 and $450 \mathrm{mg} \mathrm{l}^{-1}$ (Figs. 4 \& 5). The temperature response curves showed the highest $H^{\prime}$ and $D$ at $25^{\circ} \mathrm{C}$ (Figs. $4 \& 5$ ).

\subsection{Effects of habitat variables on species composition}

The MGLM results showed month, depth, rock and srm bottom type, and the interaction of longitude and latitude significantly influenced reef fish composition (Table 4). All these variables explained $18 \%$ variation in the reef fish community among our survey sites.

The biplot of residual ordination from the JSDM distinguished no obvious clusters of sites based on species composition (Fig. 6). The residual correlations (Fig. 7) showed that $H$. agrammus was positively correlated with Pagrosomus major; Apogon semilineatus was positively correlated with $S$. marmoratus and Microcanthus strigatus; and S. marmoratus was positively correlated with $M$. strigatus.
Table 4. Results of the multivariate generalized linear model. Significant variables $(\mathrm{p}<0.05)$ are in bold. DO: dissolved oxygen; sr: sand and rock; srm: sand, rock, and mud

\begin{tabular}{|lcc|}
\hline & Wald value & $\mathrm{p}$ \\
\hline (Intercept) & $\mathbf{4 . 9 4}$ & $\mathbf{0 . 0 1}$ \\
February & 0.99 & 0.54 \\
March & 1.79 & 0.15 \\
April & $\mathbf{2 . 3 6}$ & $\mathbf{0 . 0 4}$ \\
May & $\mathbf{2 . 9 3}$ & $\mathbf{0 . 0 2}$ \\
June & $\mathbf{2 . 9 4}$ & $\mathbf{0 . 0 2}$ \\
July & 2.32 & 0.11 \\
August & 2.19 & 0.13 \\
September & 2.31 & 0.1 \\
October & 1.18 & 0.37 \\
November & 1.49 & 0.26 \\
December & 0.61 & 0.76 \\
Depth & $\mathbf{4 . 7 1}$ & $\mathbf{0 . 0 2}$ \\
Salinity & 2.95 & 0.53 \\
DO & 3.88 & 0.14 \\
Temperature & 4.1 & 0.08 \\
Rock & $\mathbf{5 . 6 6}$ & $\mathbf{0}$ \\
Sand & 2.64 & 0.1 \\
sr & 0.67 & 0.45 \\
srm & 3.62 & $\mathbf{0 . 0 3}$ \\
Chl a & 2.85 & 0.58 \\
Longitude $\times$ Latitude & $\mathbf{5 . 0 3}$ & $\mathbf{0 . 0 2}$ \\
Depth $\times$ DO & 4.09 & 0.08 \\
\end{tabular}




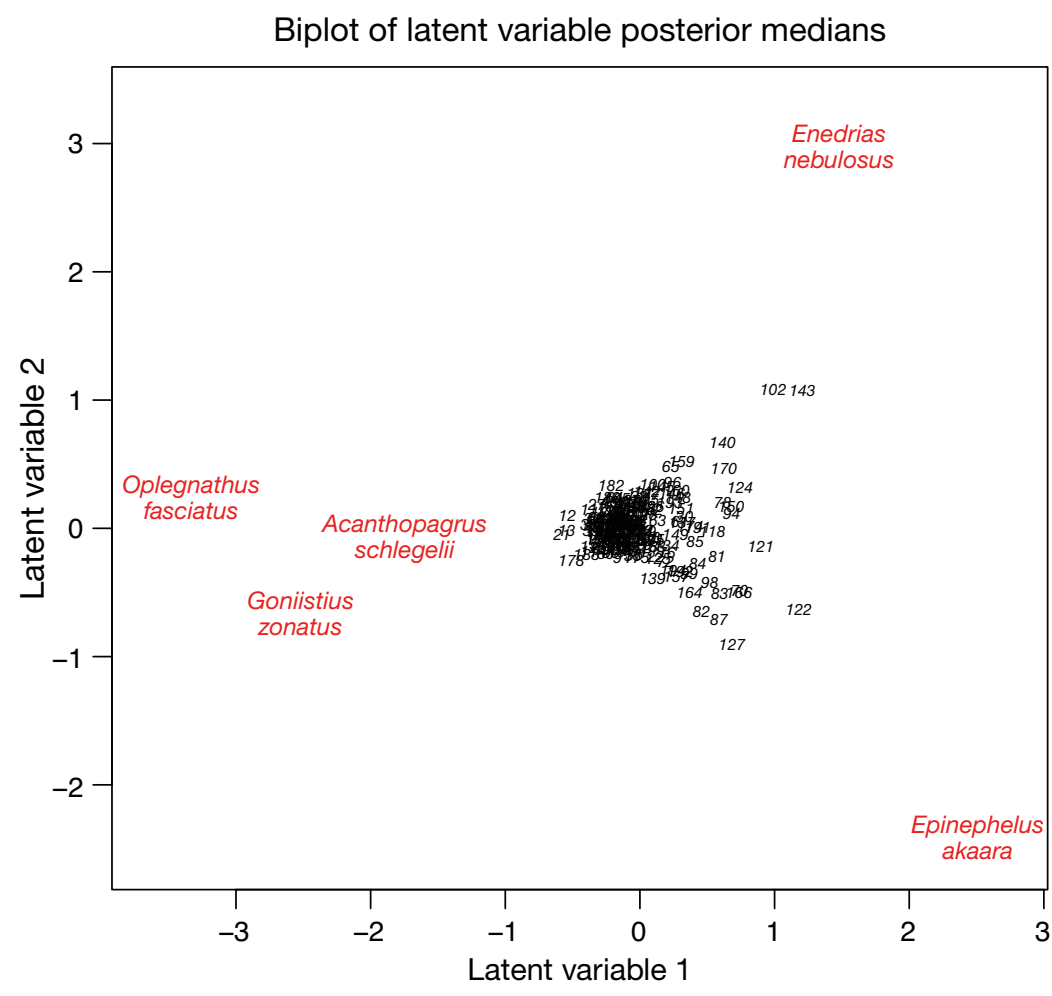

Fig. 6. Unconstrained ordination of sites and species coefficients. Sites are numbered. Only the 5 most important species are plotted (i.e. those with the strongest response to the latent variables). Species in the same direction and far from the origin are more correlated

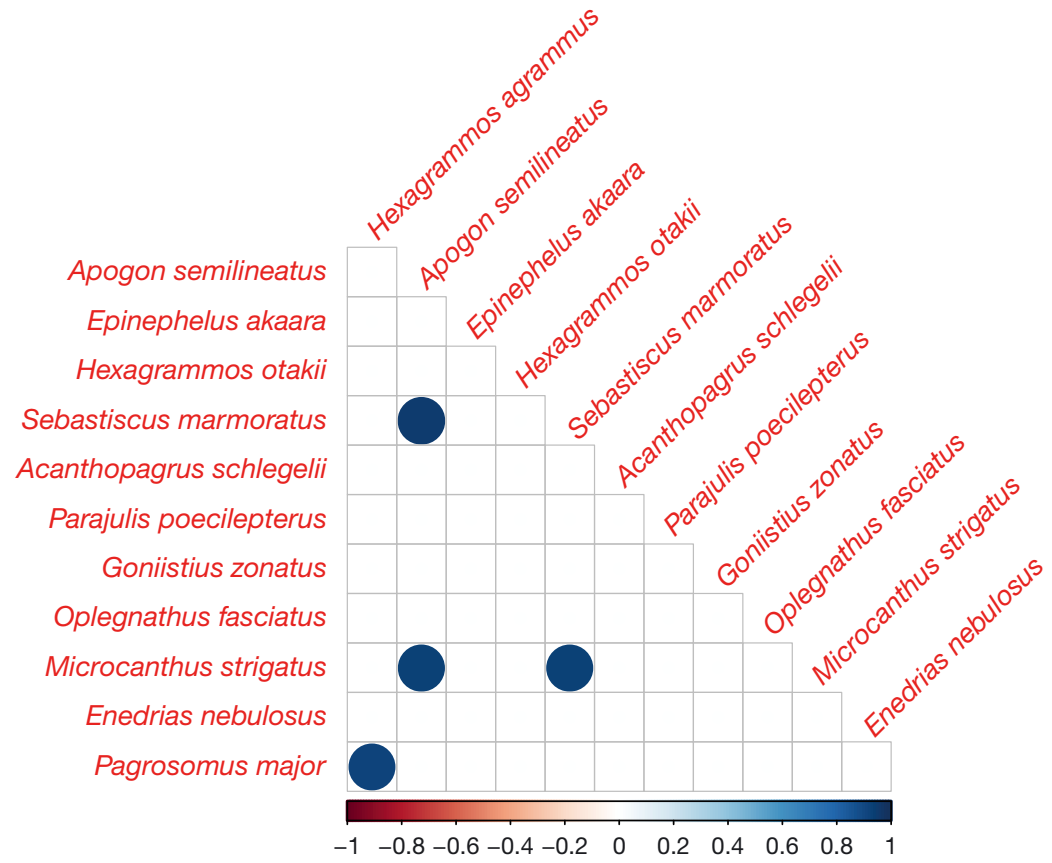

Fig. 7. Residual correlation matrix from the joint species distribution model showing significant correlations between reef fish due to their shared response to habitat variables

\section{DISCUSSION}

\subsection{Habitat effects on reef fish diversity in Ma'an Archipelago}

The reef fish diversity along the coast of Ma'an Archipelago was significantly influenced by habitat vari-

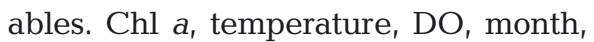
bottom type, the interaction of longitude and latitude, and the interaction of depth and DO had significant effects on $S$, while month, bottom type, chl $a$, and temperature significantly influenced $H^{\prime}$ and $D$.

In general, the number of fish species increases with chl a since higher levels of chl a support more zooplankton, on which of the fish rely for food (Badsi et al. 2010). However, our GAM results showed that $S$ decreased with chl a levels between 50-200 and 250$450 \mathrm{mg} \mathrm{l}^{-1} ; H^{\prime}$ and $D$ also decreased with chl $a$ between 50 and $450 \mathrm{mg} \mathrm{l}^{-1}$ (Figs. 3-5). Zhao et al. (2013) also found that fish diversity decreased as chl a increased in Ma'an Archipelago. The negative relationship between chl $a$ and reef fish diversity found in this study might be influenced by $S$. marmoratus, the most abundant species collected by the gillnet survey, which had a significant effect on the biodiversity indices of reef fish. Zeng et al. (2016) found that $S$. marmoratus was negatively influenced by $\mathrm{chl} a$ at levels $>50 \mathrm{mg} \mathrm{l}^{-1}$. All these negative correlations between chl $a$ and fish diversity were likely the result of a lack of food for the fishes, because Ma'an Archipelago is located in an upwelling core area in an environment where zooplankton are not abundant even though the chl $a$ is high (He et al. 1984). The highest levels of $S, H^{\prime}$, and $D$ at $25^{\circ} \mathrm{C}$ were expected, since the preferred temperature of these warm water fish is higher than $20^{\circ} \mathrm{C}$.

Reef fish diversity (including $S, H^{\prime}$ and $D$ ) varied among months and bottom types. Higher diversity was found in May and November along the coast of Ma'an Archipelago. This may be a re- 
sult of the inshore-offshore movement of reef fish during different life stages, such as the movement of adult $S$. marmoratus to offshore areas for foraging and gestation during spring, fall, and winter; this species would not be caught by the gillnet survey conducted in the inshore areas during these times (Massutí et al. 2001, Mitamura et al. 2009, Wu et al. 2012). The higher reef fish diversity in November was likely due to the inshore movement of reef fish for recruitment, as the average total length of fish caught during November was $3.1 \mathrm{~cm}$ (much smaller than their mature length) (Wu et al. 2012, Ji 2014). Bottom type also significantly influenced $S_{i}$ rock bottoms were associated with the highest $S$, as reef fish prefer rocky habitats (AburtoOropeza \& Balart 2001, Barros 2005). Kelp also provides feeding and spawning ground for most species of reef fish that inhabit rocky reefs (Zhao et al. 2013).

The interaction between depth and DO was the most important habitat variable for $S$ (Table 3). The highest $S$ occurred in areas with shallower depths and lower DO. A decrease in reef fish density and richness with increasing depth was also found in Kimbe Bay, Papua New Guinea (MacDonald et al. 2016). This depth-related decline was expected because the biological coverage (e.g. kelp) decreased with depth in Ma'an Archipelago (Bi et al. 2013), and shallow reef areas can act as fish nurseries (Parsons et al. 2016). The negative correlation between DO and fish diversity identified in our study was consistent with a previous study in Ma'an Archipelago (Zhao et al. 2013). These negative correlations may be caused by the large number of mussel farms operating along the coast of Ma'an Archipelago. The aquaculture infrastructure leads to lower DO in the water, but can also provide shelter for reef fish (Zhao et al. 2013).

The higher $S$ observed in the southern Ma'an Archipelago was also consistent with a previous study (Zhao et al. 2013). This association was likely due to the higher kelp coverage in the southern part of the study area (Zhang et al. 2008), which provides a feeding ground for reef fish (Wang et al. 2013). A positive correlation between reef fish and macroalgae has been acknowledged in temperate rocky reefs (Parsons et al. 2016). Therefore, the kelp coverage may be a potential contributor to the southern concentration of reef fish in Ma'an Archipelago.

\subsection{Habitat effects on reef fish community composition}

Effects of habitat variables on species composition are important for diverse fish assemblages when multiple species respond to these factors. In this study, the JSDM indicated that there was a minor shared response to habitat variables (Fig. 7), with multiple species responding to month, depth, bottom type, and location (interaction of longitude and latitude) (Table 4). These habitat factors explained only $18 \%$ of the variation in species composition among survey sites, which indicates that the reef fish composition was weakly influenced by our candidate habitat variables. This result, combined with the residual correlation between species derived from the JSDM, suggests that the reef fish community may be influenced by other habitat factors such as habitat complexity (which can influence the habitat use of reef fish; Bassett et al. 2018, Higgins \& Mehta 2018) or species interactions (which can also have an effect on community structure; Collie \& DeLong 1999, Shin \& Cury 2001, Collie et al. 2008). Thus, future studies examining the effects of habitat on reef fish composition should consider habitat complexity and species interactions. Additionally, the small sample size in this study may not have encompassed the entire distribution of reef fish, which resulted in no shared environmental responses. Our results suggest that the spatial scale of the reef sites examined here can be considered as one type of reef, with insufficient patterns in reef fish composition to distinguish clear reef 'zones' based on their habitat characteristics.

\subsection{Management implications}

One goal of EBFM is to enhance fish diversity and richness by conserving their potential habitats and other ecosystem factors (Link 2002). EBFM requires a robust understanding of community structure and the habitat associations of targeted fish species. Our habitat models identified the most significant habitat variables driving reef fish diversity and community composition, and also identified the most suitable environment for them. Although the data were based on historical sampling (in 2009), our results revealed insights into patterns of species' interactions and spatial distributions. The absence of data concerning reef fish has motivated a recent interest in examination of the historical record (Hilary 2013) because it can be useful for guiding future management decisions (Bennion et al. 2004, Stoddard et al. 2006).

MPAs are a conservation tool used worldwide, and evidence has shown that zoning has a significant influence on their effectiveness (Ban et al. 2017, 


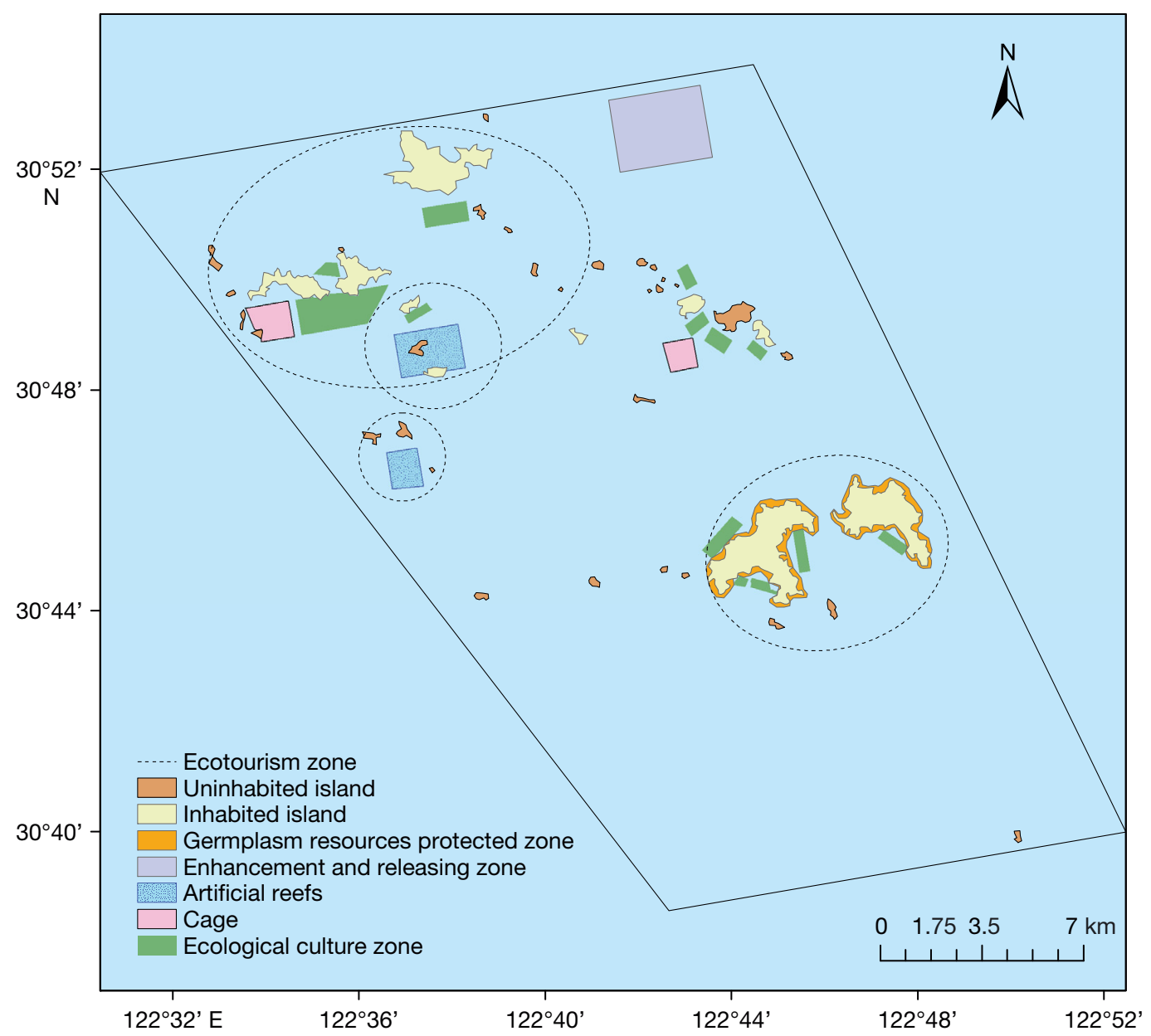

Fig. 8. Zoning of Ma'an Archipelago marine protected area

Hargreaves-Allen et al. 2017). MPA zoning is based on habitat characteristics, the distribution of the targeted species, and conservation objectives (La Mesa et al. 2010). Associations between species and habitats will provide information about the essential habitat of targeted species, which is vital for MPA zoning. There is no specific zone for reef fish in the Ma'an Archipelago MPA, as their protection was not a primary objective of this MPA (Fig. 8). Given the environmental pressures and commercial value of reef fish, conservation is needed for these species. The southern study area can be given priority as a conservation zone for reef fish because reef fish aggregate in this area (Fig. 3). In Ma'an Archipelago, the fishing season is closed from 1 May to 1 September. According to our study, to protect reef fish, fishing activities should also be restricted in November. Our findings are also valuable for artificial reef research. Artificial reefs were deployed in Ma'an Archipelago as a part of a fisheries enhancement program. However, there is considerable uncertainty about how their design and location will influence the associated fish assemblage. Our results suggest that the increased ability to host kelp and the shallow depth of artificial reefs will increase the total number of associated reef fish.

Acknowledgements. The study was done in Y.C's lab at the University of Maine and financially supported by the Shanghai Ocean University Gaoyuan Project. We thank Dongyan Han and Lei Xing from the Chen lab for their feedback and suggestions. This research was funded by the National Key R\&D Program of China (grant number: 2019YFD0901303), National Natural Science Foundation of China (grant number: 41876191) and National Key R\&D Program of China (grant number: 2018YFD0900904).

\section{LITERATURE CITED}

Aburto-Oropeza O, Balart EF (2001) Community structure of reef fish in several habitats of a rocky reef in the Gulf of California. Mar Ecol 22:283-305

Anderson MJ, Millar RB (2004) Spatial variation and effects of habitat on temperate reef fish assemblages in northeastern New Zealand. J Exp Mar Biol Ecol 305: 191-221 
Badsi H, Ali HO, Loudiki M, Hafa ME, Aamiri A (2010) Zooplankton abundance in the Massa Lagoon, Southern Morocco: impact of environmental variables. Int J Biodivers Conserv 2:289-299

Ban NC, Davies TE, Aguilera SE, Brooks C and others (2017) Social and ecological effectiveness of large marine protected areas. Glob Environ Change 43:82-91

Barros F (2005) Evaluating the importance of predation on subtidal benthic assemblages in sandy habitats around rocky reefs. Acta Oecol 27:211-223

Bassett M, Lindholm J, Garza C, Kvitek R, Wilson-Vandenberg D (2018) Lingcod (Ophiodon elongatus) habitat associations in California: implications for conservation and management. Environ Biol Fish 101:203-213

Beger M, Possingham HP (2008) Environmental factors that influence the distribution of coral reef fishes: modeling occurrence data for broad-scale conservation and management. Mar Ecol Prog Ser 361:1-13

Bennion H, Fluin J, Simpson GL (2004) Assessing eutrophication and reference conditions for Scottish freshwater lochs using subfossil diatoms. J Appl Ecol 41: 124-138

Bi YX, Zhang SY, Wu ZL (2013) Seasonal variations of Sagassum horneri distribution around Gouqi Island of East China. Shengtaixue Zazhi 32:1255-1259 (in Chinese)

Borcard D, Gillet F, Legendre P (2011) Numerical ecology with R: exploratory data analysis. Springer, New York, NY

Cameron MJ, Lucieer V, Barrett NS, Johnson CR, Edgar GJ (2014) Understanding community-habitat associations of temperate reef fishes using fine-resolution bathymetric measures of physical structure. Mar Ecol Prog Ser 506: 213-229

Chen LR, Zhang SY, Chen Y, Zhao X, Zhou XJ, Chen YZ (2015) Life history and morphology of Sargassum horneri from the Sargassum seaweed bed of Gouqi Island. Shuichan Xuebao 39:1218-1229 (in Chinese)

Collie JS, DeLong AK (1999) Multispecies interactions in the Georges Bank fish community. In: Ecosystem approaches for fisheries management. Proc Symp Ecosystem Considerations in Fisheries Management, Sep 30-Oct 3, 1998. Alaska Sea Grant, Fairbanks, AK, p 187-210

Collie JS, Wood AD, Jeffries HP (2008) Long-term shifts in the species composition of a coastal fish community. Can J Fish Aquat Sci 65:1352-1365

Connell S, Jones G (1991) The influence of habitat complexity on postrecruitment processes in a temperate reef fish population. J Exp Mar Biol Ecol 151:271-294

Froese R, Pauly D (2019) FishBase. https://fishbase.cn/search. php (accessed 13 Jan, 2019)

*García-Charton J, Pérez-Ruzafa A, Sánchez-Jerez P, BayleSempere J, Reñones O, Moreno D (2004) Multi-scale spatial heterogeneity, habitat structure, and the effect of marine reserves on Western Mediterranean rocky reef fish assemblages. Mar Biol 144:161-182

*Guidetti P, Bianchi CN, Chiantore M, Schiaparelli S, Morri C, Cattaneo-Vietti R (2004) Living on the rocks: substrate mineralogy and the structure of subtidal rocky substrate communities in the Mediterranean Sea. Mar Ecol Prog Ser 274:57-68

* Guisan A, Zimmermann NE (2000) Predictive habitat distribution models in ecology. Ecol Modell 135:147-186

*Hargreaves-Allen VA, Mourato S, Milner-Gulland EJ (2017) Drivers of coral reef marine protected area performance. PLOS ONE 12:e0179394
He D, Yang G, Shen W, Liu H (1984) Zooplankton ecology research in upwelling area along Zhejiang coast: I. Species distribution and diversity of zooplankton. Acta Oceanol Sin 9:617-626 (in Chinese)

*Higgins B, Mehta R (2018) Distribution and habitat associations of the California moray (Gymnothorax mordax) within Two Harbors, Santa Catalina Island, California. Environ Biol Fishes 101:95-108

Hilary FB (2013) Evidence of habitat associations and distribution patterns of rockfish in Puget Sound from archival data (1974-1977). MSc thesis, University of Washington, Washington, DC

Hixon MA, Beets JP (1993) Predation, prey refuges, and the structure of coral-reef fish assemblages. Ecol Monogr 63: 77-101

*Hui FK (2016) Boral-Bayesian ordination and regression analysis of multivariate abundance data in R. Methods Ecol Evol 7:744-750

Jaureguizar A, Wiff R, Clara ML (2016) Role of the preferred habitat availability for small shark (Mustelus schmitti) on the interannual variation of abundance in a large South-

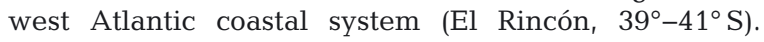
Aquat Living Resour 29:305

Ji DP (2014) Study on the fishery biology of Hexagrammos agrammus and Hexagrammos otakii in Lidao Rongcheng. PhD dissertation, Ocean University of China, Qingdao

* Johnson DW (2006) Predation, habitat complexity, and variation in density-dependent mortality of temperate reef fishes. Ecology 87:1179-1188

La Mesa G, Molinari A, Tunesi L (2010) Coastal fish assemblage characterisation to support the zoning of a new marine protected area in north-western Mediterranean. Ital J Zool 77:197-210

Lin S (2017) Legislative background: the first legislation of Zhoushan to lock in marine protection. Zhejiang Provincial People's Congress, Standing Committee of Zhejiang Provincial People's Congress, Zhejiang, 5:44-46 (in Chinese)

Link JS (2002) What does ecosystem-based fisheries management mean? Fisheries (Bethesda, Md) 27:18-21

Love MS, Schroeder DM, Lenarz W, MacCall A, Bull AS, Thorsteinson L (2006) Potential use of offshore marine structures in rebuilding an overfished rockfish species, bocaccio (Sebastes paucispinis). Fish Bull 104:383-390

*MacDonald C, Bridge TCL, Jones GP (2016) Depth, bay position and habitat structure as determinants of coral reef fish distributions: Are deep reefs a potential refuge? Mar Ecol Prog Ser 561:217-231

* Massutí E, Moranta J, De Sola LG, Morales-Nin B, Prats L (2001) Distribution and population structure of the rockfish Helicolenus dactylopterus (Pisces: Scorpaenidae) in the western Mediterranean. J Mar Biol Assoc UK 81: 129-141

*Mitamura H, Uchida K, Miyamoto Y, Arai N and others (2009) Preliminary study on homing, site fidelity, and diel movement of black rockfish Sebastes inermis measured by acoustic telemetry. Fish Sci 75:1133-1140

*Nash KL, Abesamis RA, Graham NAJ, McClure EC, Moland E (2016) Drivers of herbivory on coral reefs: species, habitat and management effects. Mar Ecol Prog Ser 554: 129-140

Neira R, Cantera JR (2005) Composición taxonómica y distribución de las asociaciones de equinodermos en los ecosistemas litorales del Pacifico Colombiano. Rev Biol Trop 53(Suppl 3):195-206 
Parker S, Berkeley S, Golden J, Gunderson D and others (2000) Management of Pacific rockfish. Fisheries (Bethesda, Md) 25:22-30

Parker SJ, Mcelderry HI, Rankin PS, Hannah RW (2006) Buoyancy regulation and barotrauma in two species of nearshore rockfish. Trans Am Fish Soc 135:1213-1223

* Parsons DF, Suthers IM, Cruz DO, Smith JA (2016) Effects of habitat on fish abundance and species composition on temperate rocky reefs. Mar Ecol Prog Ser 561:155-171

R Development Core Team (2019) R: a language and environment for statistical computing. R Foundation for Statistical Computing, Vienna

Richardson LE, Graham NA, Pratchett MS, Hoey AS (2017) Structural complexity mediates functional structure of reef fish assemblages among coral habitats. Environ Biol Fishes 100:193-207

Sadovy Y (2005) Trouble on the reef: the imperative for managing vulnerable and valuable fisheries. Fish Fish 6: 167-185

Schroeter SC, Reed DC, Raimondi PT (2015) Effects of reef physical structure on development of benthic reef community: a large-scale artificial reef experiment. Mar Ecol Prog Ser 540:43-55

Shin YJ, Cury P (2001) Exploring fish community dynamics through size-dependent trophic interactions using a spatialized individual-based model. Aquat Living Resour 14: $65-80$

Smith JA, Cornwell WK, Lowry MB, Suthers IM (2017) Modelling the distribution of fish around an artificial reef. Mar Freshw Res 68:1955-1964

Stoddard JL, Larsen DP, Hawkins CP, Johnson RK, Norris RH (2006) Setting expectations for the ecological condition of streams: the concept of reference condition. Ecol Appl 16:1267-1276

Sun XY (2018) Study on management effectiveness evaluation of national marine protected areas. MSc thesis, Shanghai Ocean University (in Chinese)

Tupper M, Boutilier RG (1997) Effects of habitat on settlement, growth, predation risk and survival of a temperate reef fish. Mar Ecol Prog Ser 151:225-236

Tuya F, Wernberg T, Thomsen MS (2009) Habitat structure affect abundances of labrid fishes across temperate reefs in south-western Australia. Environ Biol Fishes 86: 311-319

Tweedie MCK (1984) An index which distinguishes between some important exponential families. In: Ghosh JK, Roy J (eds) Statistics: applications and new directions. Proc Indian Statistical Institute Golden Jubilee Int Conf. Indian Statistical Institute, Calcutta, p 579-604

Editorial responsibility: Victor Benno Meyer-Rochow, Oulu, Finland
Wang ZH, Zhang SY, Chen QM, Xu Q, Wang K (2012) Fish community ecology in rocky reef habitat of Ma'an Archiplego. I. Species composition and diversity. Shengwu Duoyangxing 20:41-50 (in Chinese)

*Wang ZH, Zhao J, Wang K, Zhang SY (2013) Fish community ecology in rocky reef habitat of Ma'an Archipelago. II. Spatio-temporal patterns of community structure. Acta Ecol Sin 33:6218-6226 (in Chinese)

*Warfe DM, Barmuta LA (2004) Habitat structural complexity mediates the foraging success of multiple predator species. Oecologia 141:171-178

*Warton DI, Blanchet FG, O'Hara RB, Ovaskainen O, Taskinen S, Walker SC, Hui K F C (2015) So many variables: joint modeling in community ecology. Trends Ecol Evol 30:766-779

Wood S (2005) Estimate predictor contribution in GAM models. https://stat.ethz.ch/pipermail/r-help/2005-September/079944.html (accessed 13 Jan 2019)

Wood SN (2017) Generalized additive models: an introduction with R. Chapman and Hall/CRC, New York, NY

Wood S, Wood MS (2007) The mgcv package. http://cran.rproject.org/web/packages/mgcv/mgcv.pdf (accessed 13 Jan 2019)

Wu Z L, Wang Z H, Wang K, Zhang S Y (2012) Preliminary study on biological characteristics of reef fish Sebasticus marmoratus of Ma'an Archipelago. Guandong Agric Sci 12:139-143 (in Chinese)

Yamanaka KL, Logan G (2010) Developing British Columbia's inshore rockfish conservation strategy. Mar Coast Fish 2:28-46

Yi W, Ulrike N, Wright ST, Warton DI (2012) mvabund: an R package for model-based analysis of multivariate abundance data. Methods Ecol Evol 3:471-474

Zeng X, Zhang SY, Wang ZH, Lin J, Wang K (2016) Habitat suitability assessment of Sebasticus marmoratus in the rocky reef region of the Ma'an Archipelago. Acta Ecol Sin 36:3765-3774 (in Chinese)

Zhang QL, Wang F, Zhao WH, Tang XH (2007) Seasonal characteristics in the water masses in Zhoushan fishing ground and adjacent region. Acta Oceanol Sin 29:1-9 (in Chinese)

K Zhang SY, Liang J, Wang ZH, Wang K (2008) Distribution characteristics of benthic algae in intertidal zone of Ma'an Archipelago of Zhejiang Province. Ying Yong Sheng Tai Xue Bao 19:2299-2307 (in Chinese)

Zhao J, Zhang SY, Wang ZH, Lin J, Zhou XJ, Jiang RJ (2013) Fish community diversity distribution and its affecting factors based on GAM model. Shengtaixue Zazhi 32: 3226-3235 (in Chinese)

Submitted: September 25, 2019; Accepted: July 6, 2020 Proofs received from author(s): October 12, 2020 